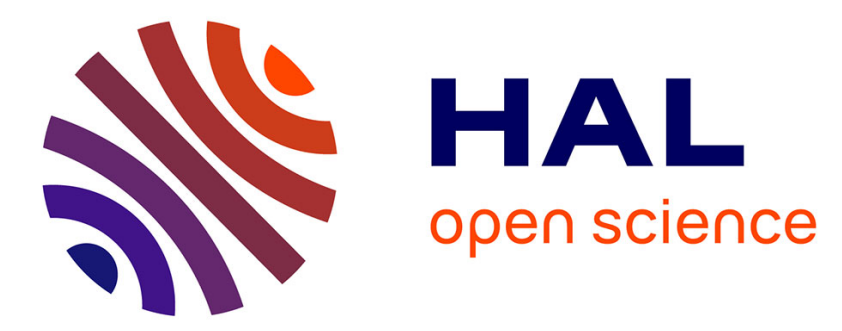

\title{
Microstructural design of new high conductivity - high strength Cu-based alloy
}

\author{
Stéphane Gorsse, Blanche Ouvrard, Mohamed Gouné, Angeline \\ Poulon-Quintin
}

\section{- To cite this version:}

Stéphane Gorsse, Blanche Ouvrard, Mohamed Gouné, Angeline Poulon-Quintin. Microstructural design of new high conductivity - high strength Cu-based alloy. Journal of Alloys and Compounds, 2015, 633, pp.42-47. 10.1016/j.jallcom.2015.01.234 . hal-01122713

\section{HAL Id: hal-01122713 \\ https://hal.science/hal-01122713}

Submitted on 9 Jan 2019

HAL is a multi-disciplinary open access archive for the deposit and dissemination of scientific research documents, whether they are published or not. The documents may come from teaching and research institutions in France or abroad, or from public or private research centers.
L'archive ouverte pluridisciplinaire HAL, est destinée au dépôt et à la diffusion de documents scientifiques de niveau recherche, publiés ou non, émanant des établissements d'enseignement et de recherche français ou étrangers, des laboratoires publics ou privés.

\section{(ㅇ)(1) $\$$}

Distributed under a Creative Commons Attribution - NonCommercial - NoDerivatives 44.0 


\title{
Microstructural design of new high conductivity - high strength Cu-based alloy
}

\author{
S. Gorsse*, B. Ouvrard, M. Gouné, A. Poulon-Quintin \\ CNRS, Université de Bordeaux, ICMCB, \\ 87 avenue du Docteur Albert Schweitzer, 33608 Pessac Cedex, France
}

\begin{abstract}
:
Some novel high conductivity-high strength materials were designed in the binary $\mathrm{Cu}-\mathrm{Mg}$. They exhibit an excellent balance between strength and electrical properties. The properties and the performance of the designed materials are compared with the main Cu-based alloys and the analysis shows that they perform equally to the best one ( $\mathrm{Cu}-\mathrm{Be})$. Furthermore, we show that an increase of $\mathrm{Mg}$ content modifies the microstructure feature and leads to a strong increase of strength without any significant deterioration of the electrical conductivity. This behavior was attributed to the formation of eutectic islands in which high density of $\mathrm{Cu} 2 \mathrm{Mg}$ nanoparticles precipitate.
\end{abstract}

\section{Introduction}

Copper-based high strength conductive alloys are used in a myriad of applications in automotive, aeronautic and electronic industries such as conductive springs, interconnections, etc [1]. The demand of these materials is booming, partly driven by the increase use of copper in existing applications but also by energy and environmental considerations where their uses in emerging applications such as electrical propulsion and renewable energy are essential. The strongest conductive alloy is based on the Cu-Be system 
[2] which has the disadvantage of toxicity and cost. There is a great demand for the replacement of $\mathrm{Cu}$-Be alloys by new toxic free and environmentally friendly high strength-high conductivity materials.

Among the different approaches proposed to develop high strength and increase electrical conductivity of $\mathrm{Cu}$ alloys, severe plastic deformation leading to ultrafine grained microstructure and nanoscale precipitation of a secondary phase are the most investigated for solute having a very limited solubility in $\mathrm{Cu}$ such as $\mathrm{Cu}-\mathrm{Cr}[3,4,5]$ and $\mathrm{Cu}-\mathrm{Ag}[6]$, for example. In an attempt to find an alternative, we focused on the Cu-Mg system for two main reasons (1) Mg affects only weakly the electrical conductivity of $\mathrm{Cu}$ [7] and (2) in contract with $\mathrm{Cu}-\mathrm{Cr}$ and $\mathrm{Cu}-\mathrm{Ag}$, it provides several degree of freedom to generate microstructures (eutectic transformation, driving forces for precipitation). Studies of $\mathrm{Cu}-\mathrm{Mg}$ alloys are not numerous and mainly limited to the aging response of low alloyed compositions $[8,9,10,11]$ apart from the work of Fehrenbach et al. [12] and Fidler et al. [13] on the eutectic transformation. In order to obtain high strength - high conductivity materials, an alloy design was performed in the $\mathrm{Cu}-\mathrm{Mg}$ system from the thermodynamic properties of the studied system. Then, different compositions of $\mathrm{Mg}$ (4.1at\%, 8.1at\%, 23.1at\%) were selected and the evolution of microstructural, electrical and mechanical properties were investigated. It was shown that the obtained materials exhibit an excellent balance between strength and electrical conductivity properties and an increase of $\mathrm{Mg}$ contents leads to a strong increase of strength without any significant deterioration of the conductivity. The origin of such properties is discussed from a metallurgical point of view.

\section{Selection of the studied compositions in the $\mathrm{Cu}-\mathrm{Mg}$ binary system}


There are several experimental and thermodynamic descriptions of the $\mathrm{Cu}-\mathrm{Mg}$ system in the literature $[14,15,16]$. The most recent results agree that the Cu-Mg system consists of the liquid, the terminal solid solutions: fcc (Cu solid solution), hcp (Mg solid solution), and the intermetallic compounds $\mathrm{Cu}_{2} \mathrm{Mg}$ and $\mathrm{CuMg}_{2}$ (Fig.1). Both intermetallic phases melt congruently and are involved in eutectic reactions with either fcc or hcp solid solutions. We have used the thermodynamic parameters evaluated from the CALPHAD assessment of Coughanowr et al. [14] in which $\mathrm{Cu}_{2} \mathrm{Mg}$ is described by the sublattive model $(\mathrm{Cu}, \mathrm{Mg})_{2}(\mathrm{Cu}, \mathrm{Mg})$ and the compound energy formalism in order to reproduce the homogeneity range, whereas $\mathrm{CuMg}_{2}$ is considered as a line compound.

Adding any solute to $\mathrm{Cu}$ leads to a decrease of its electrical conductivity because the local perturbation of both the atomic and electronic structure of the perfect crystal around the impurity atoms acts as scattering centers for electrons. The scattering effect increases with the difference of size and valence between the solute and the host atoms, this is why the residual resistivity arising from impurities increases as the position of the solute element becomes distant from that of a host component in a given line of the periodic table [17]. More precisely, the residual resistivity is a function of the scattering cross section of the impurity which increases as the square of the valency difference between the impurity and the host metal [18]. In the case of $\mathrm{Mg}$, the excess valency is only of 1 which is enough to disrupt the uniform charge of $\mathrm{Cu}$ and screens the conduction electron. The magnitude of the screening radius is given by $\left(6 \pi e^{2} \rho_{0} / E_{F}\right)^{-1 / 2}$, where $\mathrm{E}_{\mathrm{F}}$ is the Fermy energy and $\rho_{0}$ the density of conduction electrons [19]. With the values of $E_{F}=7 \mathrm{eV}$ and $\rho_{0}=8.510^{28} / \mathrm{m}^{3}$ for pure $\mathrm{Cu}$, this gives a magnitude of the screening radius of about $0.055 \mathrm{~nm}$ which is much shorter than the interatomic distance of 0.255 of pure $\mathrm{Cu}$ and leads to an increase of the resistivity. According to Nordheim's rule [20] the residual resistivity is proportional to the impurity concentration. 
However, the presence of the $\mathrm{Cu}_{2} \mathrm{Mg}$ compound provides a mean to decrease the amount of the residual solute since an important fraction of $\mathrm{Mg}$ will leave the $\mathrm{Cu}$ lattice to form the corresponding secondary phase. Secondary phase particles scatter electrons too with an effect that depends on their size and spacing (compared to the electron mean free path), though not as much as solute atoms.

In order to evaluate the effect of the microstructure (solute atoms, secondary phase, grain boundaries) on properties, three alloy compositions were selected to cover the main features of the Cu-Mg phase diagram (see Figure 1):

(1) Cu-4.1at\%Mg, on cooling this alloy will not cross the eutectic line leading to the formation of a single-phase fcc-Cu solid solution of composition identical to that of the alloy,

(2) Cu-8.1at\%Mg, on cooling the liquid phase will reach the eutectic composition and the alloy will end in the two-phase field fcc- $\mathrm{Cu}+\mathrm{Cu}_{2} \mathrm{Mg}$,

(3) Cu-23.1at\%Mg that is close to the eutectic composition.

\section{Experimental procedure}

The Cu-Mg alloys were prepared by induction melting of $\mathrm{Cu}(99.99 \%)$ and $\mathrm{Mg}(99.9 \%)$ pieces in a glassy carbon crucible under argon. This way, small ingots with $16 \mathrm{~mm}$ in diameter and 30 $\mathrm{mm}$ in height were obtained. Metallographic examination was performed by scanning electron microscopy (SEM) on a polished sample. Phase identification was made using X-ray diffraction (XRD) and electron probe microanalysis (EPMA).

The electrical conductivity was determined at room temperature by the linear four probe method and the hardness by Vickers micro-indentation [21]. A load of $1.96 \mathrm{~N}$ was applied with 
a rate of $40 \mu \mathrm{m} / \mathrm{s}$ and maintained during 20 seconds. Each measurement was taken 10 times.

This hardness have been converted to yield strength from the Taylor Factor [22].

\section{Experimental results and discussion}

Figure 2 presents the SEM backscattered electron (BSE) images of the $\mathrm{Cu}-4.1 \mathrm{at} \% \mathrm{Mg}, \mathrm{Cu}-$ 8.1at\%Mg and $\mathrm{Cu}-23.1 \mathrm{at} \% \mathrm{Mg}$ alloy compositions in the as-cast condition. The phase with the lowest mean atomic number (Mg content) appears darkest in the image. The sample $\mathrm{Cu}$ 8.1at\%Mg consists of Cu-rich dendrites surrounded by a lamellar structure of alternating Curich (bright) and Mg-rich (dark) phases. The interlamellar spacing is about $0.8 \mu \mathrm{m}$ and the size of the dendrites is about $23 \mu \mathrm{m}$. EPMA indicates that the mean composition of the dendrites is 4.3 at.\% $\mathrm{Mg}$, the bright lamella is 7.7 at.\% $\mathrm{Mg}$, and the dark lamella is 31.5 at.\% $\mathrm{Mg}$. The analysis of the XRD spectra shown in the Figure $\mathbf{3}$ indicates that the microstructure is composed by a solid solution of fcc- $\mathrm{Cu}(\mathrm{Mg})$ and the intermetallic compound $\mathrm{Cu}_{2} \mathrm{Mg}$.

The samples $\mathrm{Cu}-4.1 \mathrm{at} \% \mathrm{Mg}$ consists of the single-phase fcc-Cu(Mg) solid solution having the nominal composition of the alloy. The microstructure of the $\mathrm{Cu}-23.1 \mathrm{at} \% \mathrm{Mg}$ is composed of a fully lamellar aggregates of alternating fcc- $\mathrm{Cu}(\mathrm{Mg})$ with composition 7.7at\% $\mathrm{Mg}$ and $\mathrm{Cu}_{2} \mathrm{Mg}$ phases with a constant lamellar spacing of about $1 \mu \mathrm{m}$. The measured compositions of the lamellae in the eutectic aggregates are reported in the Figure $\mathbf{1}$ (see black circle).

Both these latter and the formation of a lamellar pattern typical of an eutectic transformation confirm the phase fields, the invariant reaction and the solubility limits of the calculated CuMg phase diagram in the Cu-rich side.

Two different morphologies can be distinguished for second phase (here $\mathrm{Cu}_{2} \mathrm{Mg}$ ) particles at grain boundaries of matrix (here $\mathrm{Cu}$ ). Indeed, the lens-like shape would be favored if the grain 
boundary energy of grains in the matrix per unit area is smaller (two times at least) than the energy per unit of the $\mathrm{Cu} / \mathrm{Cu}_{2} \mathrm{Mg}$ interphase boundary. Otherwise, a layer of $\mathrm{Cu}_{2} \mathrm{Mg}$ phase wets continuously the $\mathrm{Cu} / \mathrm{Cu}$ grain boundary for the reason that the growing $\mathrm{Cu}_{2} \mathrm{Mg}$ phase particle tends to increase its surface. Even if the grain boundary wetting has already been observed in phase transformations such as both the eutectoid and eutectic transformations $[23,24]$, in our study, we did not observe any particular wetting of $\mathrm{Cu}_{2} \mathrm{Mg}$ at any grain boundary (see Figure 2). This situation is radically different from that one observed in a fully eutectic microstructure in the Zn-Al system [24]. A close examination of the Figure 2 shows the complete coverage of primary $\mathrm{Cu}_{2} \mathrm{Mg}$ grain by copper. However, this is a minor and does not accurately reflect the final microstructure feature. Furthermore, it is worth noting that the morphology of the $\mathrm{Cu}_{2} \mathrm{Mg}$ shall be mainly determined by the morphology of $\mathrm{Cu}$ that is mainly lenticular with a large range of aspect ratio. In other words, the resulting microstructure feature is very similar to that one of pearlite in steels in which lamella of $\mathrm{Fe}_{3} \mathrm{C}$ is embedded in $\alpha$-Fe matrix.

The proportion of the eutectic aggregates evaluated from image analysis of the $\mathrm{Cu}-8.1 \mathrm{at} \% \mathrm{Mg}$ alloy is 25 vol.\% that is 28 mol.\%. which is above the 8 mol.\% calculated under equilibrium condition (lever rule). This difference may arise from a kinetics effect. Indeed, the composition of the solid as a function of the fraction of the solid is given by the scheil-Gulliver equation : $C_{s}=k C_{0}\left(1-f_{s}\right)^{k-1}$, where $C_{s}$ is the composition of the solid, $C_{0}$ is the nominal composition, $k$ is the partition coefficient ( $k=C_{s} / C_{l}$, with $C_{l}$ the liquid composition) and $f_{s}$ is the fraction of the solid.

Figure 4 shows the calculated composition changes as a function of the fraction of solid: as the amount of solid increases during solidification, the $\mathrm{Mg}$ concentration of the liquid increases until it reaches the eutectic composition $C_{E}$ to form a lamellar structure. Therefore, 
The fraction of the eutectic aggregates can be obtained when the composition of the liquid is equal to the eutectic composition ( 0.21 at fraction). The Figure 4 shows that this situation happens when the fraction of the eutectic phase is about 30 mol.\%. This latter is in very good agreement with the experimentally determined one (28 mol.\%).

The analysis performed by Electron Probe MicroAnalyser given in Figure $\mathbf{5}$ evidences a gradient of $\mathrm{Mg}$ composition around the eutectic islands. The $\mathrm{Mg}$ content being much higher close to the interface between eutectic islands and $\mathrm{Cu}$ than in the bulk (6.9 at\% vs 3.1at \%).

Since the amount of $\mathrm{Mg}$ in the alloy is above the maximum solubility of $\mathrm{Mg}$ in $\mathrm{Cu}$, it can be reasonably supposed that precipitation of a second phase occurs during cooling. In order to check this assumption, some analysis by TEM were performed on the $\mathrm{Cu}-23.1 \mathrm{at} \% \mathrm{Mg}$ alloy. The results given in Figure 6 evidence the presence of nanoparticles in $\mathrm{Cu}$. The TEM images show a high density of particles having a very small mean size (around $5 \mathrm{~nm}$ to $15 \mathrm{~nm}$ ). The comparison between the obtained Selected Area Electron Diffraction pattern (Figure 7) of a zone located in copper lamellar and some simulated diffraction pattern of $\mathrm{Cu}_{2} \mathrm{Mg}$ along various zone axis, would indicate that precipitates correspond to $\mathrm{Cu}_{2} \mathrm{Mg}$. This high density of particles observed in our samples can be explained by the enhancement of the driving force for $\mathrm{Cu}_{2} \mathrm{Mg}$ nucleation close to the interface resulting to a higher $\mathrm{Mg}$ content as observed in

\section{Figure 5.}

Figure $\mathbf{8}$ shows the bubble chart (Ashby's diagram) of yield strength and electrical conductivity for the alloys prepared in this study in comparison with the main Cu-based alloys. It is observed that the addition of $\mathrm{Mg}$ to $\mathrm{Cu}$ leads to a decrease of its electrical conductivity and an increase of its yield strength. The importance of this effect depends on the amount of $\mathrm{Mg}$ and then on the resulting microstructure. One can see that the present Cu-Mg alloys occupy the same field than Cu-Be alloys which suggest that they perform equally well with respect to this 
combination of properties. It is also noticeable that the $\mathrm{Cu}-23.1 \mathrm{at} \% \mathrm{Mg}$ alloy exhibit an exceptionally high yield strength combined with a good electrical conductivity.

The decrease of the electrical conductivity of copper with the addition of $\mathrm{Mg}$ is due to the scattering of electrons. Mg solute atoms act as scattering centers, when their number increases the electron mean free path decreases. The effect is very significant between pure copper and the $\mathrm{Cu}-4.1 \mathrm{at} \% \mathrm{Mg}$ alloy since all the $\mathrm{Mg}$ added goes into solid solution. For compositions above the solubility limit, the additional amount of $\mathrm{Mg}$ is removed from the liquid to form the $\mathrm{Cu}_{2} \mathrm{Mg}$ compound. This explains why there is only a slight decrease of the electrical conductivity from 4.1 to $23.1 \mathrm{at} \% \mathrm{Mg}$.

In order to explain this high value of the yield strength, we have adapted a mechanical model initially developed to describe the mechanical behavior of perlite, an eutectoid microstructure composed by lamella of $\mathrm{Fe}_{3} \mathrm{C}$ [25]. Indeed, a parallel can be drawn between the microstructure of the present copper alloy in which grains of fcc-Cu(Mg) and lamellar eutectic aggregates replace the ferrite and the pearlite in low carbon steels. From this model it is possible to account the hardening contribution that arise from:

- the solid solution, it depends on the amount of $\mathrm{Mg}$ solute into the copper grains,

- the grain boundaries, this is the so-called Hall-Petch hardening being inversely proportional to the square root of the grain size,

- the eutectic aggregates leading to hardening by composite effect, it is related to the interlamellar spacing and the volume fraction of the eutectic structure.

For the Cu-4.1at\%Mg alloy, which consists of a single-phase solid solution with grain size of 23 $\mu \mathrm{m}$, the evolution of the flow stress $\sigma_{C u}$ as a function of the strain $\varepsilon_{C u}$ is expressed as follows [25]: 


$$
\sigma_{C u}\left(\varepsilon_{C u}\right)=\sigma_{0}^{C u}+\frac{\alpha \mu M \sqrt{b}}{\sqrt{d}} \sqrt{\frac{1-\exp \left(-f M \varepsilon_{C u}\right)}{f}}
$$

with $\alpha$ a constant equals to $0.4, M$ the Taylor factor $(M=3), \mu$ the shear modulus of copper $(\mu$ $=46 \mathrm{GPa}), b$ the Burger's vector $(b=0.255 \mathrm{~nm})$ and $d$ the mean copper grain size $(d=23 \mu \mathrm{m})$. $f$ is an adjustable parameter taken from [25]. $\sigma_{0}{ }^{\mathrm{Cu}}$ is the summation of the intrinsic lattice resistance, a value of $40 \mathrm{MPa}$ is used (pure copper) [2], and the solid solution strengthening effect that arises from the addition of $\mathrm{Mg}$ atoms in the $\mathrm{Cu}$ lattice. This effect is proportional to the amount of solute and can be evaluated as $C X_{\mathrm{ss}}$, where $X_{\mathrm{ss}}$ is the mole fraction of $\mathrm{Mg}$ in solid solution and $C=49 \mathrm{MPa} / \mathrm{X}$ to reproduce the measured value of the yield strength for the $\mathrm{Cu}-4.1$ at\%Mg (Fig. 9). We can conclude from this result that the contribution arising from $\mathrm{Mg}$ solute atoms is the dominant hardening mode in the single phase $\mathrm{Cu}-4.1 \mathrm{at} \% \mathrm{Mg}$ alloys.

The increase of the amount of $\mathrm{Mg}$ solutes leads to the formation of lamellar aggregates in the Cu-8.1at\%Mg alloy due to the eutectic transformation. The law to describe the strengthening effect of the lamellar pattern is expressed as follows [25]:

$$
\sigma_{\text {eut }}\left(\varepsilon_{\text {eut }}\right)=\sigma_{0}^{\text {eut }}+\frac{\mu M b}{S}+\frac{K}{g}\left(1-\exp \left(-\frac{g \varepsilon_{\text {eut }}}{2}\right)\right)
$$

Where $K$ and $g$ are two empirical constants taken from Ref.19, and $S$ is the interlamellar spacing $(S=0.8 \mu \mathrm{m})$, and $\sigma_{0}^{\text {eut }}$ is the critical stress due to the lattice friction in the copper lamellae of the eutectic aggregates. From the measured $\mathrm{Mg}$ concentration in the copper lamella and the value of $C$ (proportionality coefficient for the solid solution strengthening effect) determined from the analysis of the $\mathrm{Cu}-4.1 \mathrm{at} \% \mathrm{Mg}$ alloy, the numerical value of $\sigma_{0}^{\text {eut }}$ is $418 \mathrm{MPa}$.

As shown in Figure 9, the summation of the different strengthening contributions arising from the intrinsic lattice resistance, the solid solution, the grain boundaries, and the eutectic 
aggregates leads to a value of about $330 \mathrm{MPa}$ which is below the measured yield strength (459 $\mathrm{MPa}$ ) for the $\mathrm{Cu}-8.1 \mathrm{at} \% \mathrm{Mg}$ alloy. The same trend is observed for the $\mathrm{Cu}-23.1 \mathrm{at} \% \mathrm{Mg}$ alloy which consists of $100 \%$ of eutectic aggregates. The gap between the calculated and measured values, 524 and $1024 \mathrm{MPa}$ respectively, is even higher, and can be attributed to the distribution of precipitates as seen in the TEM dark field image in Figure 6. Indeed, it is well known that particles can have an attractive interaction with dislocation and act to pin the dislocation, giving rise to a strengthening effect. In order to evaluate the possible contribution to the strengthening provided by precipitates, one can calculate the mean particle spacing in the slip plane, $\lambda$, leading to a stress increment $\tau$ of $500 \mathrm{MPa}$ by considering the bowing of dislocations between precipitates:

$$
\lambda \approx 0.8 M \frac{\mu b}{\tau_{\text {orowan }}}
$$

where $M$ is the Taylor Factor $(M=3), \mu$ is the shear modulus of copper $(\mu=48 \mathrm{GPa})$ and $b$ is the Burgers vector $(b=0.25 \mathrm{~nm})$. The determined mean particle spacing $\lambda$ is about of $50 \mathrm{~nm}$. This value, qualitatively consistent with our TEM observations (Figure 6), requires a high density of nanoparticles in Cu matrix.

\section{Conclusion}

Some novel high conductivity - high strength materials were designed in the binary Cu-Mg. They exhibit an excellent balance between strength and electrical properties. An increase of Mg content leads to a strong increase of strength (more than $1000 \mathrm{MPa}$ ) without any 
significant deterioration of the electrical conductivity. This unexpected behavior is attributed to the formation of eutectic islands $\mathrm{Cu}_{2} \mathrm{Mg} / \mathrm{Cu}$ in which high density of $\mathrm{Cu}_{2} \mathrm{Mg}$ nanoparticles precipitate during cooling. The design material is a good alternative to the $\mathrm{Cu}$-Be system which has the disadvantage of toxicity.

The microstructure designed in the binary $\mathrm{Cu}-\mathrm{Mg}$ exhibits both a high conductivity and high strength. These properties were obtained from a classical process. The High Pressure Torsion technic would opens up new opportunities. Indeed, as nicely shown by $\left[{ }^{26}\right]$ it could be thus possible to control the precipitation state including the size of particle and the composition of the matrix by acting on the rotation angle. The latter control the properties of both strengthening and electrical properties.

\section{Acknowledgements}

The research was supported by The French National Research Agency (ANR-08-JCJC-0133). 


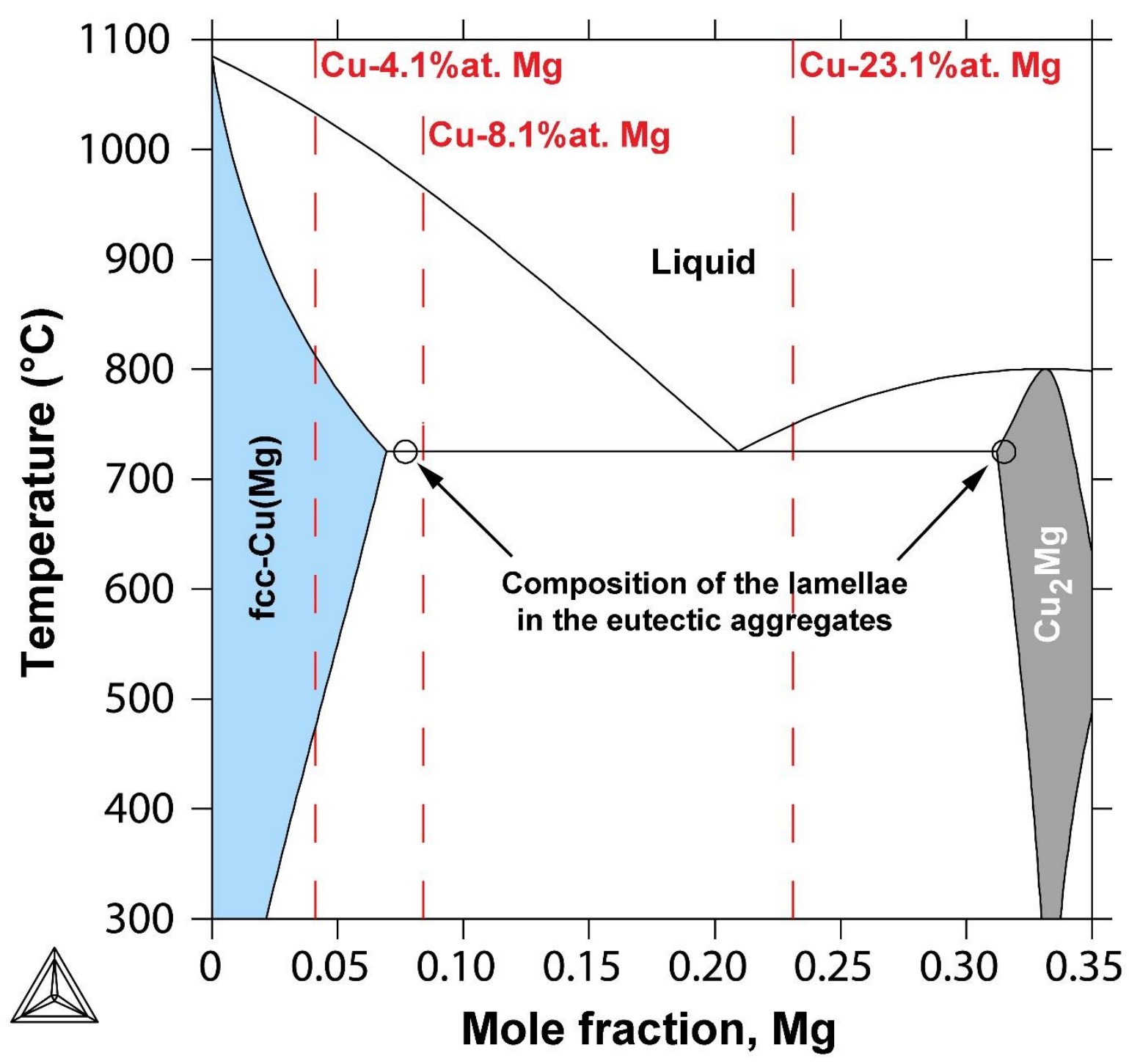

Figure 1: Binary phase diagram of the Cu-Mg system calculated using ThermoCalc and the thermodynamic evaluation of Coughanowr et al. [14]. The open circles indicate the measured composition of the lamellae in the eutectic aggregates. 


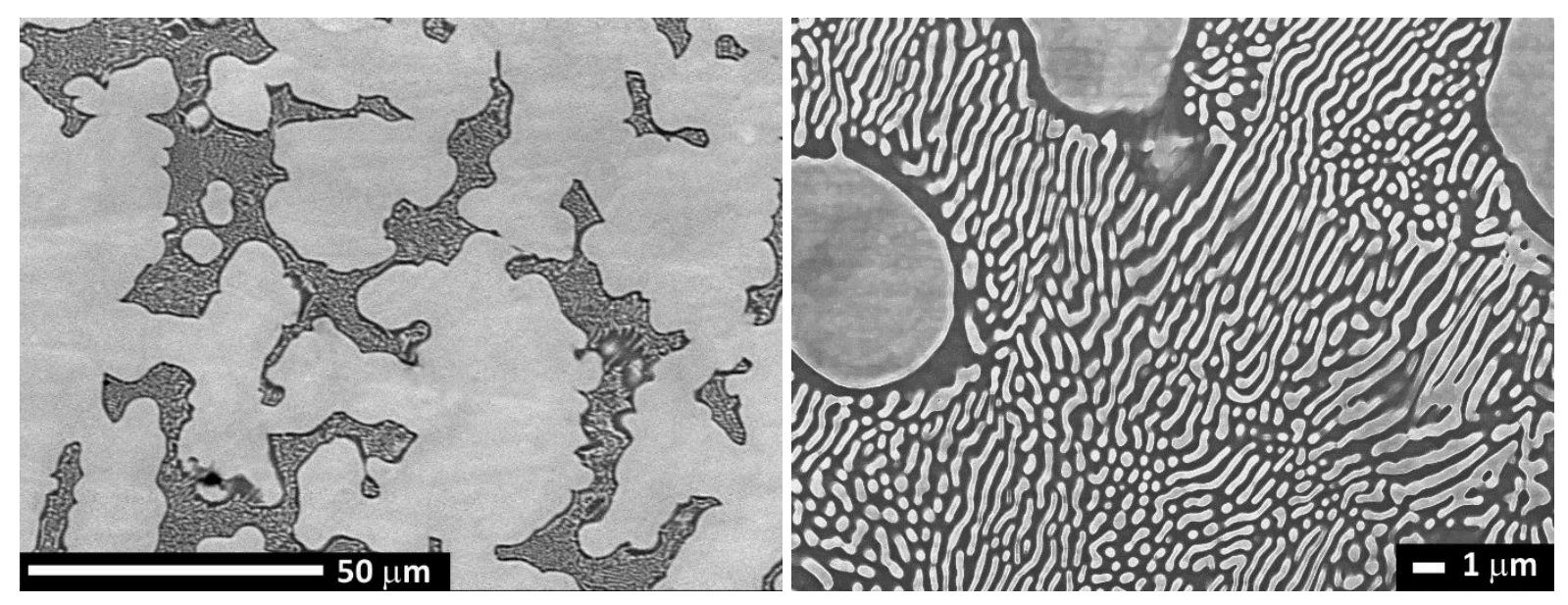

(a)

(b)

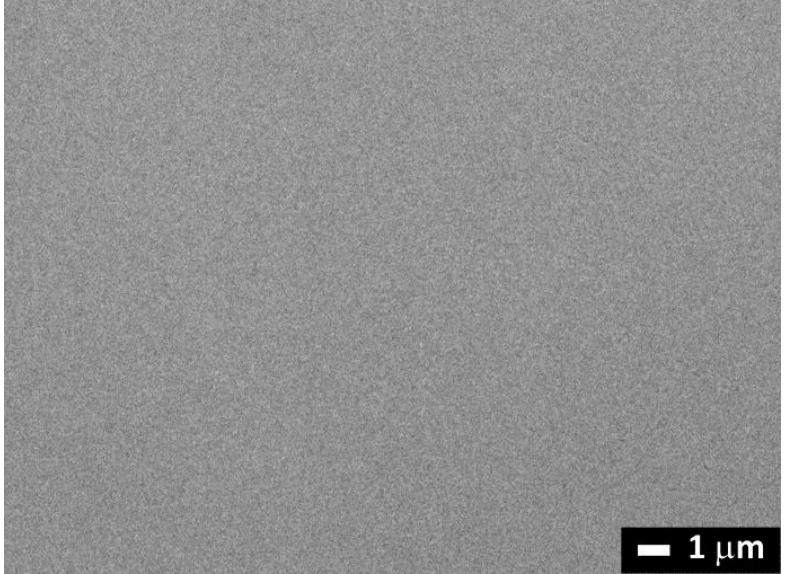

(c)

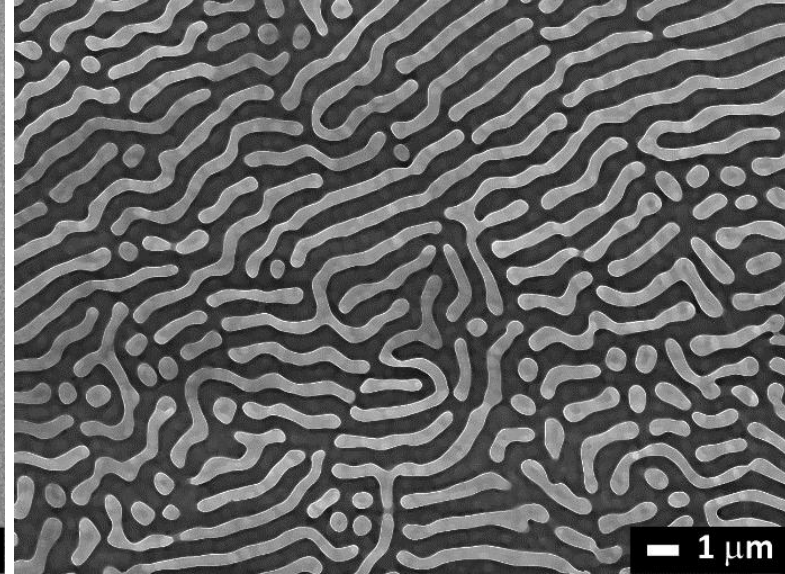

(d)

Figure 2: SEM micrographs of (a) the as-cast Cu-8.1at\%Mg alloy, (b) a zoom of the eutectic aggregates, (c) the Cu-4.1at\%Mg alloy, and (d) the Cu-23.1at\% alloy. The $\alpha-\mathrm{Cu}(\mathrm{Mg})$ solid solution and $\mathrm{Cu}_{2} \mathrm{Mg}$ appear in light and dark gray, respectively. 


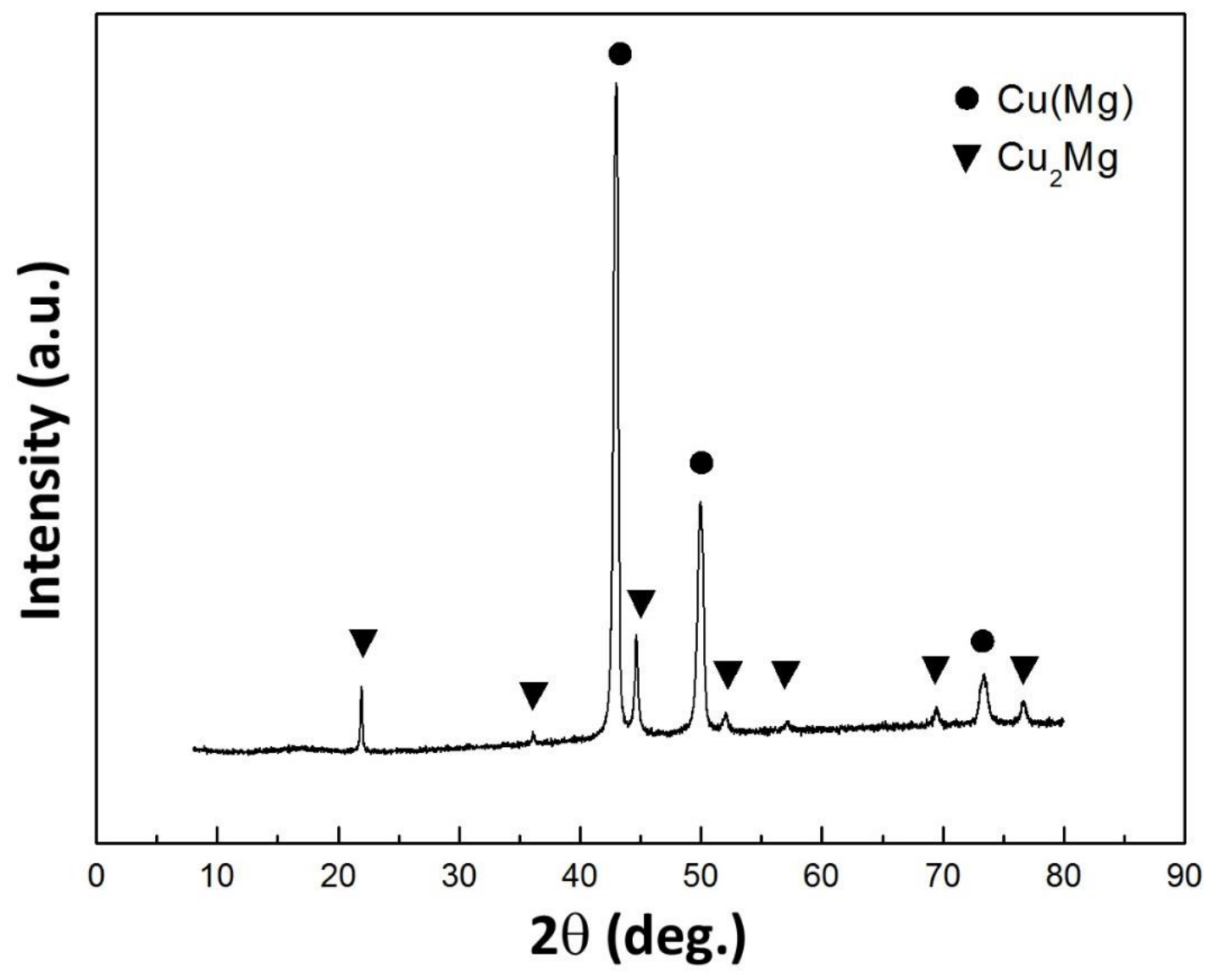

Figure 3: XRD spectra corresponding to the microstructural state shown in Fig.2a for the ascast Cu-8.1at\%Mg alloy. 


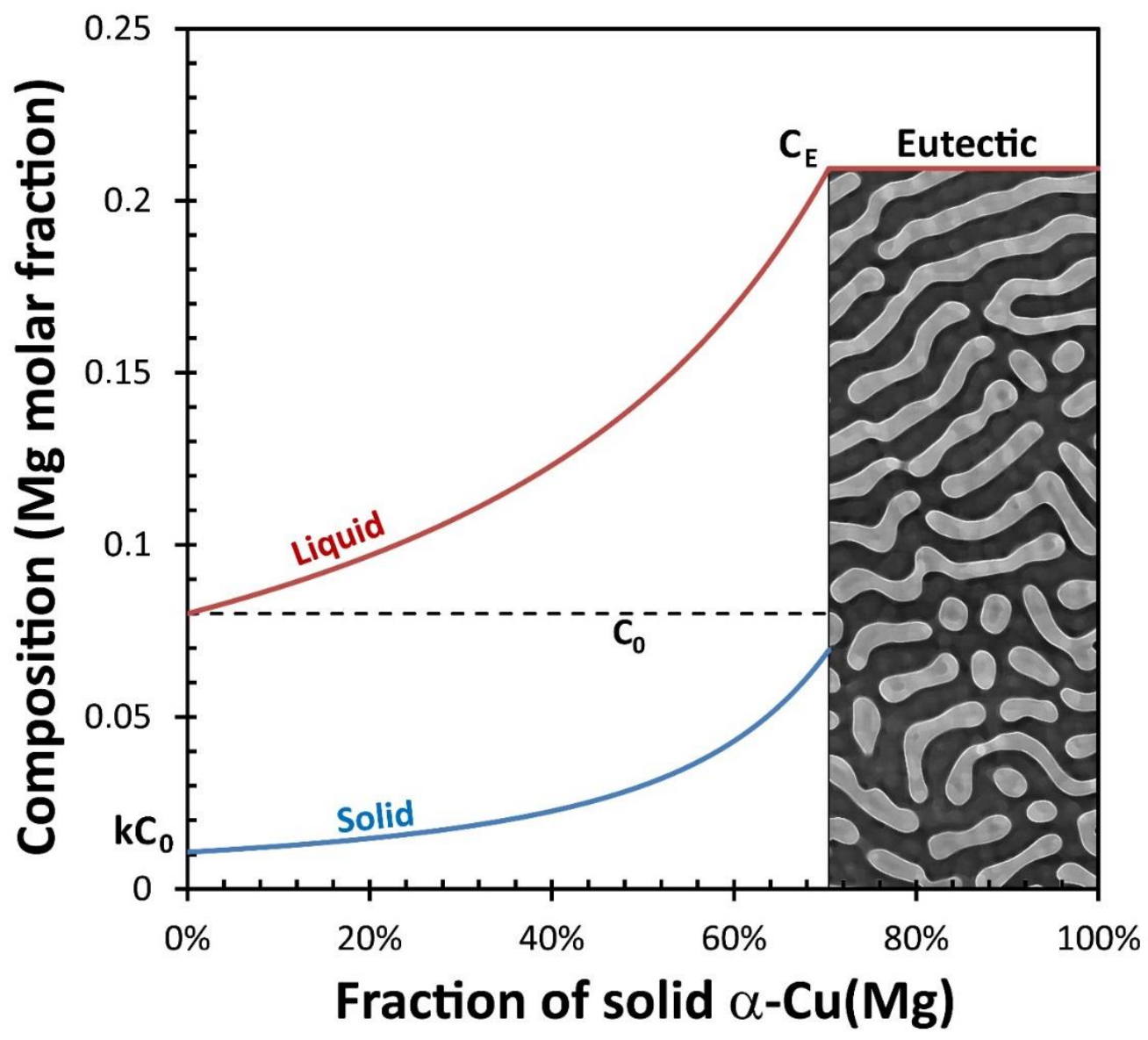

Figure 4: Solute profile according the Scheil-Gulliver equation. When the solid begins to form, the solute $(\mathrm{Mg})$ is rejected into the liquid phase ahead of the solid/liquid interface. Since it is redistributed into the liquid only by diffusion, there is an accumulation of this solute in the liquid until the eutectic composition $C_{E}$ is reached, leading to the formation of a lamellar mixture of $\alpha-\mathrm{Cu}(\mathrm{Mg})$ (light gray) and $\mathrm{Cu}_{2} \mathrm{Mg}$ (dark gray). 


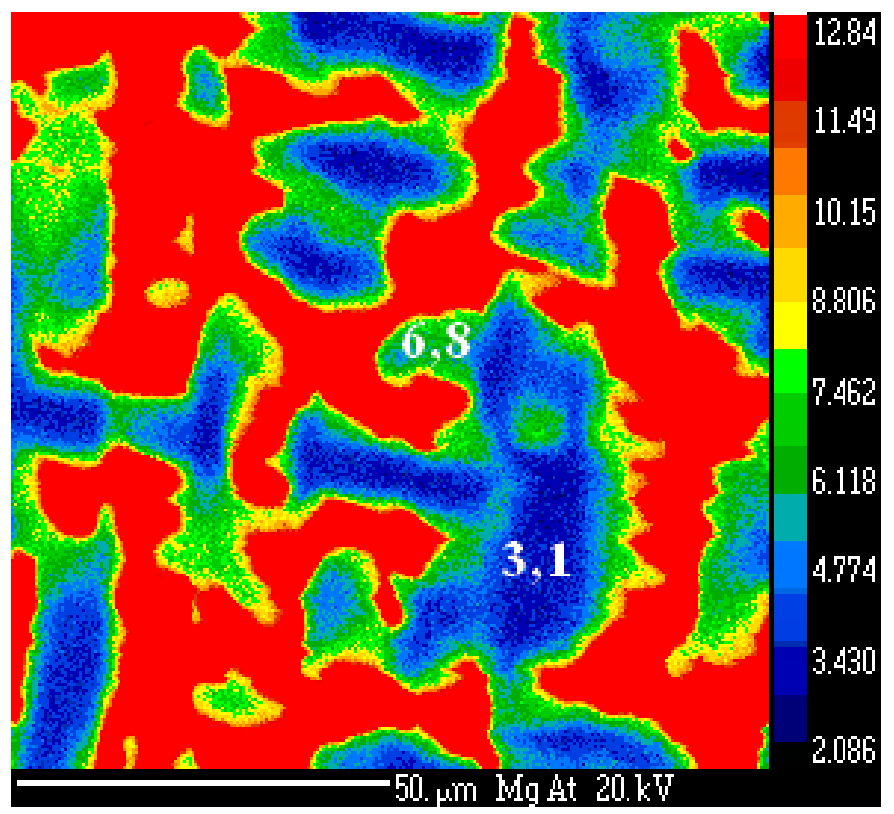

Figure 5: Analysis of the Mg content in the $\mathrm{Cu}-8.1$ at\%Mg by Electron Probe Micro Analyser.

The $\mathrm{Mg}$ content is heterogeneous in Copper. It is much more higher close to the interface between the eutectic islands (6.3 at\%) than in the bulk (3. 1at\%). 


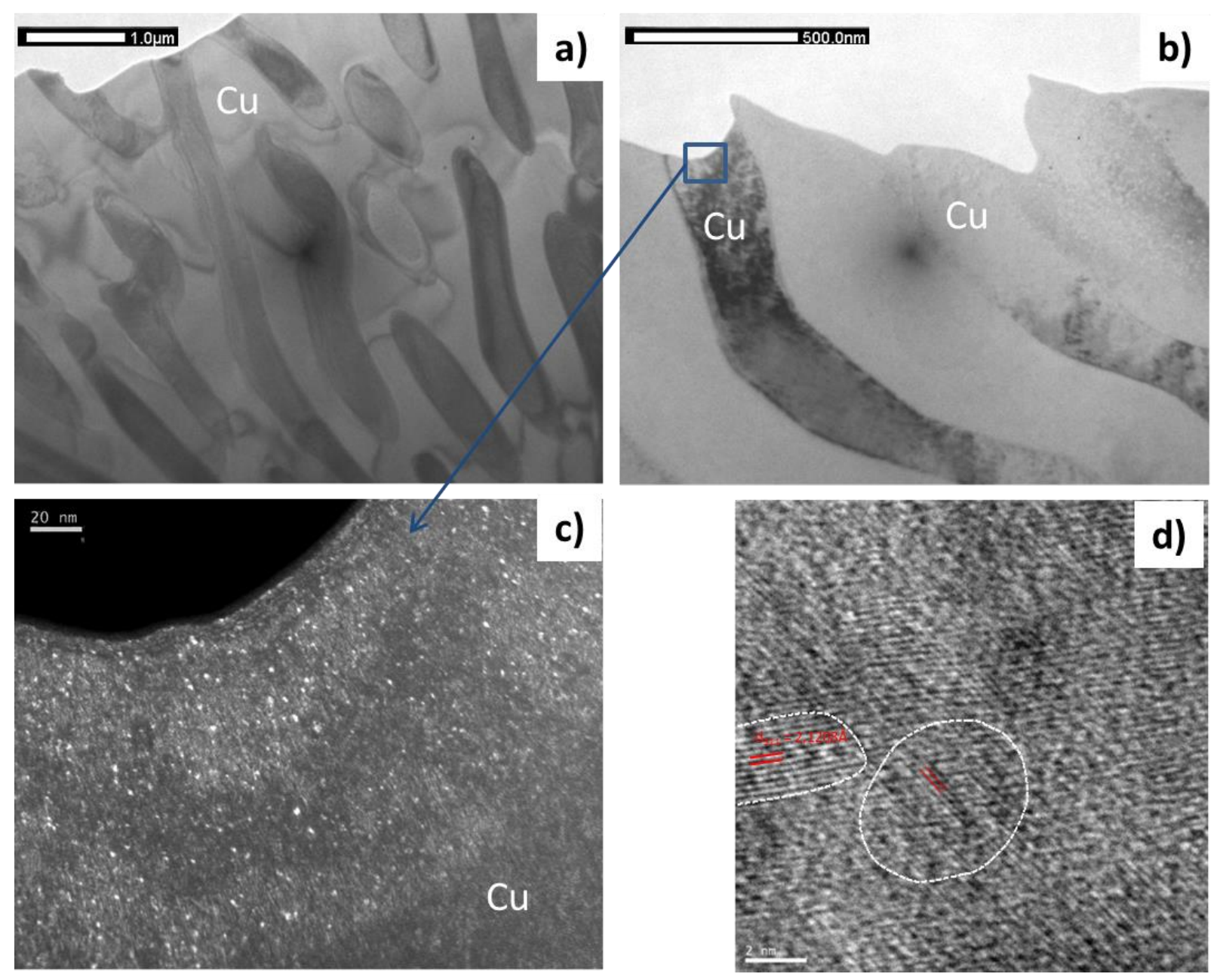

Figure 6: a) TEM images of the fully eutectic microstructure (Cu-23.1at\%Mg), b) Bright field and associated c) dark field inside the copper matrix. Both the dark field (c) and the HRTEM image (d) show the presence of high density of nanoparticles in copper identified as $\mathrm{Cu}_{2} \mathrm{Mg}$. 

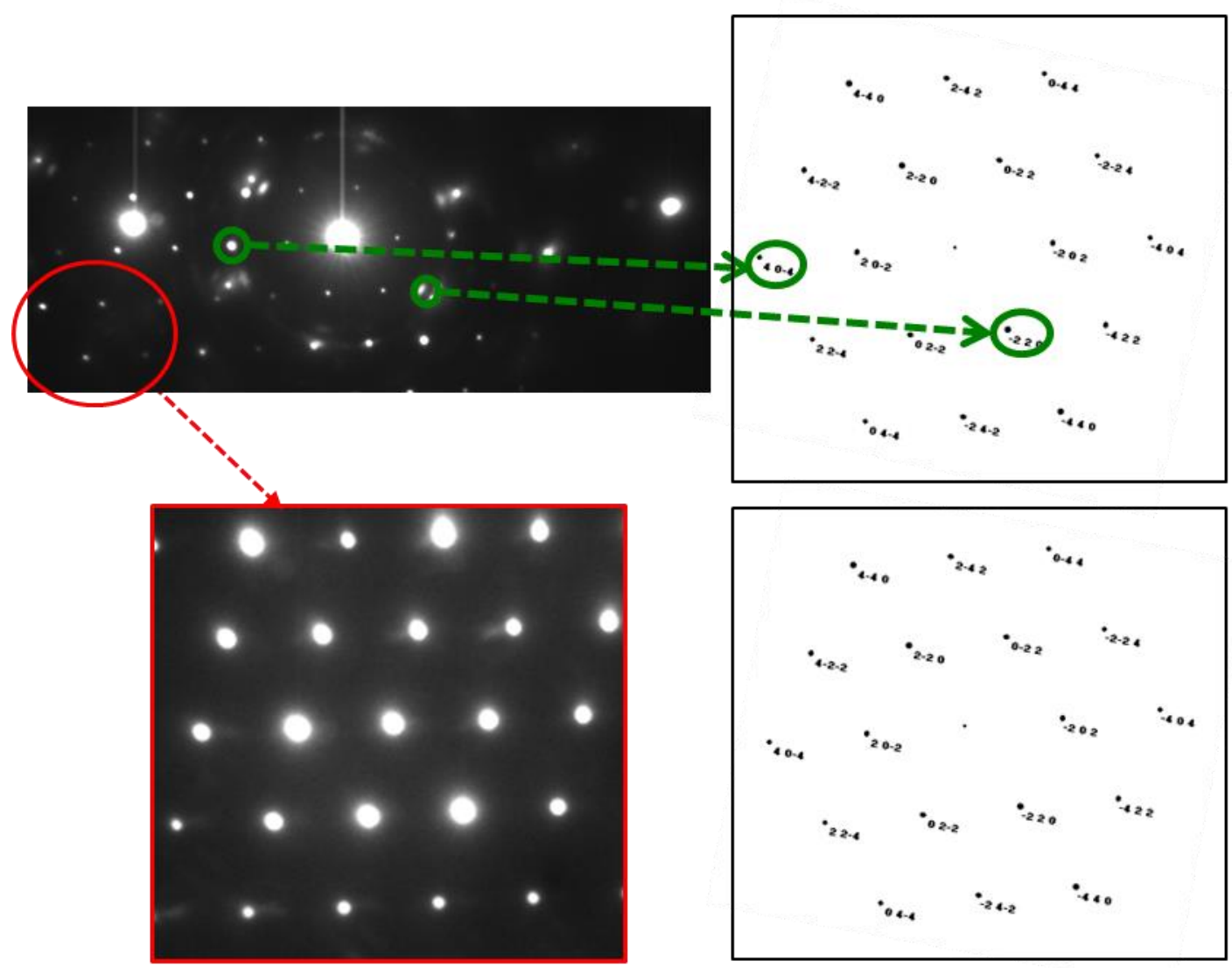

$\mathrm{Cu}_{2} \mathrm{Mg}$ [111]

Figure 7: Comparison between the obtained Selected Area Electron Diffraction and the microdiffraction pattern of $\mathrm{Cu}_{2} \mathrm{Mg}$ along different zone axis. These results would indicate that precipitates corresponds to $\mathrm{Cu}_{2} \mathrm{Mg}$. 


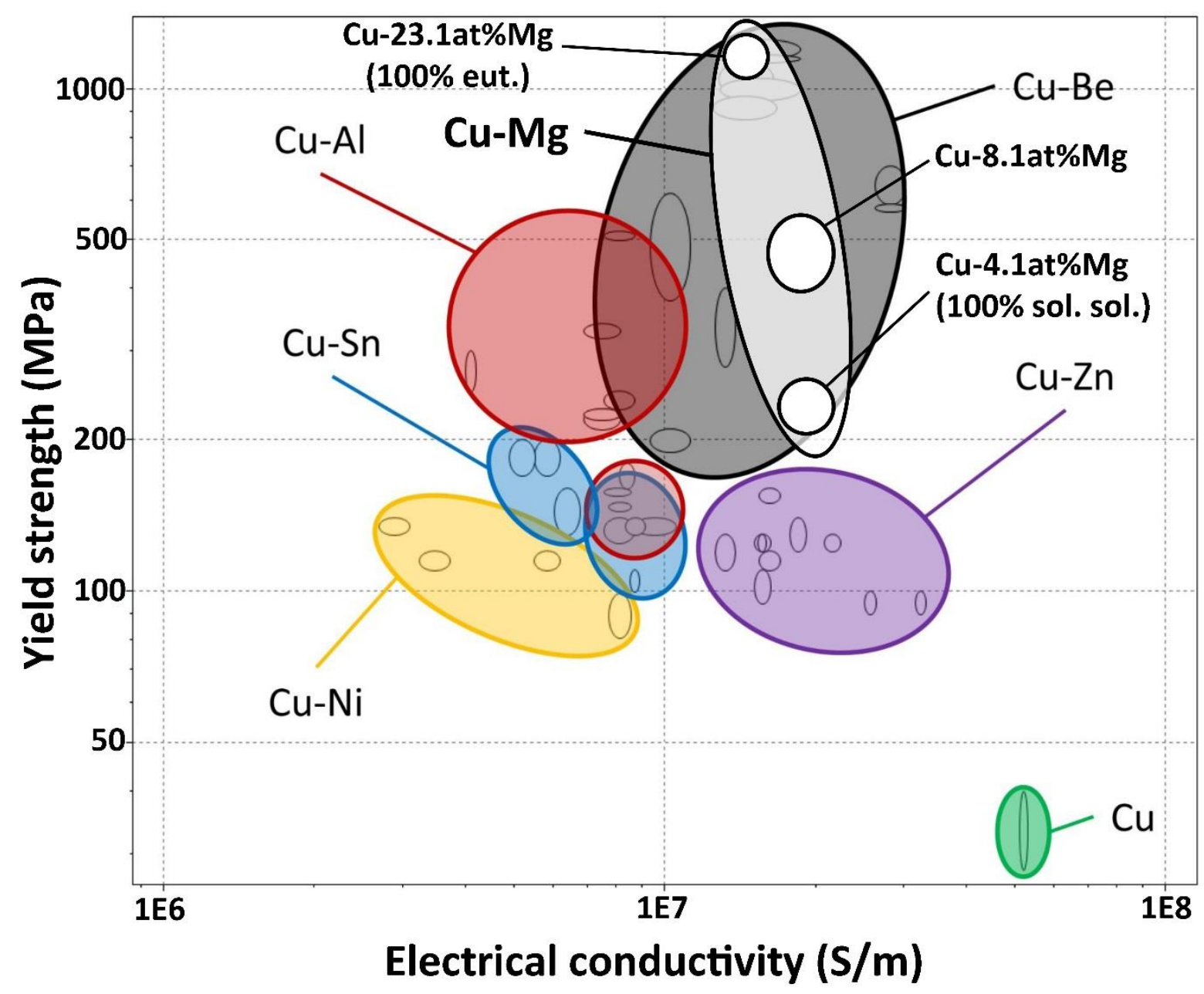

Figure 8: Logarithmic plot of the yield strength vs. electrical conductivity for copper based alloys according [2] and the casted $\mathrm{Cu}-4.1 \mathrm{at} \% \mathrm{Mg}, \mathrm{Cu}-8.1 \mathrm{at} \% \mathrm{Mg}$ and $\mathrm{Cu}-23.1 \mathrm{at} \% \mathrm{Mg}$ alloys from the present work. The best choices for high strength and high conductivity are $\mathrm{Cu}-\mathrm{Be}$ alloys and the present alloys. 


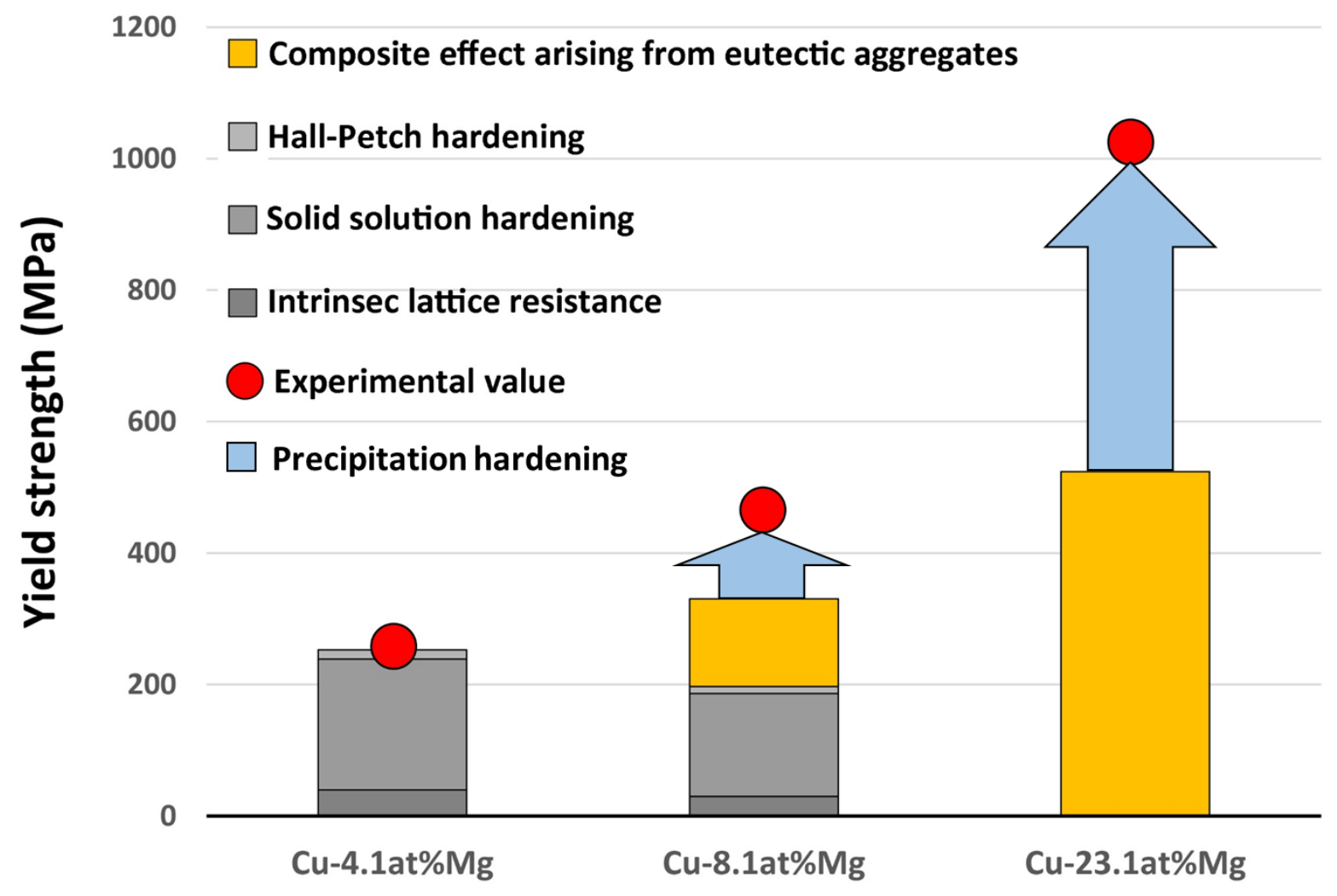

Figure 9: Calculated strengthening contributions for the casted $\mathrm{Cu}-\mathrm{Mg}$ alloys: $\mathrm{Cu}-4.1 \mathrm{at} \% \mathrm{Mg}$ is a single-phase fcc-Cu(Mg) solid solution, $\mathrm{Cu}-8.1 \mathrm{at} \% \mathrm{Mg}$ is composed of $\mathrm{fcc}-\mathrm{Cu}(\mathrm{Mg})$ and eutectic aggregates, and $\mathrm{Cu}-23.1 \mathrm{at} \% \mathrm{Mg}$ consists of fully eutectic structure. 


\section{References}

1 - Copper Applications Technology Roadmap, International Copper Association, March 2011.

2 - CES Edupack 2013 database (software), Granta Design Ltd, Cambridge, UK.

3 - N. Takata, Y. Ohtake, K. Kita, K. Kitagawab and N. Tsuji, Scripta Mater. 60 (2009) 590.

4 - R. K. Islamgaliev,1,a) K. M. Nesterov,1 J. Bourgon,2 Y. Champion,2 and R. Z. Valiev, J. Appl. Phys. 115 (2014) 194301.

5 - A. Chbihi, X. Sauvage, D. Blavette, Acta Mater. 60 (2012) 4575.

6 - K. S. Raju, V. S. Sarma, A. Kauffmann, Z. Hegeduse, J. Gubicza, M. Peterlechner, J. Freudenberger, G. Wilde, Acta Mater. 61 (2013) 228.

7 - Y. Zeng, S. Mu, P. Wu, K.P. Ong, and J. Zhang, J. Alloys Compd., 478 (2009) 345.

8 - O. Dahl, Siemens-Konzern 6 (1927) 222.

9 - H. Böhm, Z. Metallkd. 52 (1961) 564.

10 - H. Tsubakino and R. Nozato, J. Mater. Sci. 19 (1984) 3013.

11 - K.-I. Nishikawa, S. Semboshi, and T. J. Konno, Solid State Phenomena 127 (2007) 103.

12 - PJ Fehrenbach, HW Kerr, and P Niessen, J. Cryst. Growth, 18 (1973) 151.

13 - R.S Fidler, M.N Croker, and R.W Smith, J. Cryst. Growth, 13-14 (1972) 739.

14 - C. Coughanowr, I. Ansara, R. Luoma, M. Hämäläinen, H.L. Lukas, Z. Metallkd. 82 (1991) 574.

15 - T. Buhler, S.G. Fries, and P.J. Spencer, J. Phase Equilibria 19 (1998) 317.

16 - S. Gorsse and G.J. Shiflet, Calphad 26 (2002) 63.

17 - A.L. Norbury, Trans. Faraday Soc. 16 (1921) 570.

18 - G.T. Meaden, Electrical resistance of metals, Plenum Press, New York, 1965 (Chapter 5). 
19 - F. Seitz, The Modern Theory of Solids (McGraw-Hill, New York, 1940).

20 - J.S. Galsin, Kluwer/Plenum Publishers, New York, 2002, 109.

21 - P. Dordor, E. Marquestaut, C. Salducci, P. Hagenmuller, Rev. Phys. Appl. 20 (1985) 795.

22 - Y. Champion and Y. Bréchet, Adv. Eng. Mater. 12 (2010) 798.

23 - J.W. Christian, The theory of transformations in metals and alloys, Oxford: Pergamon

Press, 1975, 452.

24 - G.A. Lopez, E. J. Mittemeijer, BB. Straumal, Acta Mater. 52 (2004) 4537.

25 - S. Allain and O. Bouaziz, Mater. Sci. Eng. A 496 (2008) 329.

26 - B.B. Straumal, A. R. Kilmametov, Y. Ivanisenko, L. Kurmanaeva, B. Baretzky, Y. O.

Kucheev, P. Zieba, A. Korneva, D. A. Molodov, Materials Letters 118 (2014) 111. 